\title{
Pengaruh Model Pembelajaran Kooperatif Jigsaw Terhadap Aktivitas Belajar Siswa Pada Pelajaran IPA
}

\author{
Samsul Bahri ${ }^{1}$, Amin Mustajab ${ }^{2}$
}

1,2STKIP Melawi

\author{
Email: samsulbahri804@gmail.com, aminmustajab53@gmail.com
}

\begin{abstract}
Abstrak
Proses pembelajaran IPA di SDN 12 Entikong masih dominan terpusat pada guru, metode dan model pembelajaran kurang bervariasi. Pada pembelajaran IPA hanya diperoleh dari guru sehingga wawasan dan keatifan siswa kurang. Hal tersebut membuat siswa jenuh,, pasif, dan kurang aktif sehingga, pembelajaran tampak monoton. Tujuan penelitian untuk mengetahui pengaruh model pembelajaran Kooperatif Tipe Jigsaw terhadap aktivitas belajar siswa pada pelajaran IPA. Melalui pembelajaran Kooperatif Tipe Jigsaw diharapkan dapat melatih siswa agar terbiasa berdiskusi dan bertanggungjawab baik secara individu dalam membantu memahami materi pokok kepada teman sekelasnya. Metode penelitian yang digunakan adalah metode eksperimen, yaitu kelompok eksperimen dan kelompok kontrol. Kelompok eksperimen menggunakan pembelajaran Kooperatif Tipe Jigsaw siswa kelas IVA SDN 12 Entikong dan kelas kontrol pembelajaran konvesional siswa kelas IVB SDN 12 Entikong. Berdasarkan hasil penelitian terdapat pengaruh terhadap pembelajaran Kooperatif Tipe Jigsaw. Hasil analisis diperoleh nilai t-hitung sebesar 3,063 dan nilai t-tabel sebesar 1,063. Selain itu diketahui perbedaan skor rata-rata 2,545. Sehingga dapat disimpulkan terdapat pengaruh penerapan model pembelajaran Kooperatif Tipe Jigsaw terhadap aktivitas belajar siswa kelas IV SDN 12 Entikong.
\end{abstract}

Kata kunci: Koopeatif, Jigsaw, Aktivitas, IPA

\section{Abstract}

The science learning process at SDN 12 Entikong is still predominantly centered on the teacher, the methods and learning models are less varied. In teaching science concepts, it is only obtained from the teacher so that students' insight and activity are lacking. This makes the student bored, passive, and less active so that the learning seem monotonous. The aim of research to determine the effect of the jigsaw model of student learning activities in science lessons. Through the Jigsaw Type Cooperative learning, it is hoped that students will be accustomed to dscussing and being responsible individually in helping to understand the main material to their classmates. The method used is the experimental method, namely the experimental group and the control group. The experimental group used jigsaw type cooperative learning for grade IVA students at SDN 12 Entikong and control class for conventional learning for grade IVB students at SDN 12 Entikong. Based on the research results there is an influence on type jigsaw cooperative learning. The results of the analysis obtained the t-count value 3.063 and the t-table value of 1.063 . In addition, it is known that the difference in the average score is 2,545. So it can be concluded that there is an influence on the application of the jigsaw type cooperative learning model on the learning activities of fourth grade students of SDN 12 Entikong.

Keywords: Cooperative, Jigsaw, Activity, Science Learning

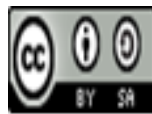




\section{Pendahuluan}

Proses pembelajaran IPA di SDN 12 Entikong masih dominan terpusat pada guru, metode yang digunakan tidak bervariasi, serta tidak menggunakan media pembelajaran akan berdampak siswa menjadi pasif, jenuh, dan fakta dan konsep IPA hanya diperoleh dari guru, dan siswa tidak dikenai tagihan. Kondisi ini terjadi karena pembelajaran IPA sehingga aktivitas belajar siswa pada sekolah tersebut tidak tercapai secara optimal.

Kemampuan siswa untuk bertahan menyelesaikan tugas, berpartisipasi secara aktif dalam kegiatan belajar, dan memperhatikan selama proses pembelajaran merupakan alat paling penting yang dapat memperkirakan keberhasilan mereka di sekolah. Belajar menjadi salah satu tugas dan kewajiban siswa agar dapat mencapai keberhasilan. Berhasil atau tidaknya siswa dalam belajar disebabkan beberapa faktor. Faktor tersebut dapat berasal dari dalam diri siswa (internal) dan dari luar siswa (eksternal).

Untuk melihat keberhasilan dalam proses pembelajaran dapat dilihat dari dua indikator yaitu keaktifan siswa pada saat proses pembelajaran dan hasil yang didapatkan siswa setelah akhir pembelajaran. (Mardian \& Sylvia, 2020). Selanjutnya, berhasil tidaknya pembelajaran di sekolah bergantung pada aktif tidaknya siswa dalam belajar. Aktivitas siswa di sekolah cukup kompleks dan bervariasi. Menurut Paul D. Dierich dalam (Sardiman, 2014) indikator aktivitas siswa dalam belajar IPA terbagi menjadi 8 kelompok aktivitas diantaranya sebagai berikut: (1) visual activities, (2) oral activities, (3) listening activities, (4) writing activities, (5) drawing activities, (6) motor activities, (7) mental activities dan, (8) emotional activities. Keaktifan ini bukan tentang kelas yang ramai dengan suara siswa, namun lebih pada banyaknya siswa yang bertanya, berpeendapat atau memberikan jawaban seputar materi yang dipelajari dengan ide-ide yang mungkin muncul berhubungan dengan konsep materi yang dipelajari. Selain itu, keaktifan siswa selama proses belajar mengajar merupakan salah satu indikator adanya keinginan atau motivasi siswa untuk belajar. Dikatakan memiliki keaktifan apabila ditemukan ciri-ciri perilaku seperti sering bertanya kepada guru atau siswa lain, mau mengerjakan tugas yang diberikan guru, maupun menjawab pertanyaan dan senang diberi tugas belajar.

Guru turut serta berperan dalam meningkatkan aktivitas siswa dalam pembelajaran. Terdapat lima upaya yang dapat diciptakan guru untuk meningkatkan keaktifan siswa dalam belajar. Menurut Sumiati dan Asra (Asra, 2009), diantaranya sebagai berikut: (1) penataan ruang, (2) penerapan prinsip belajar sambil berbuat, (3) membimbing dan mengarahkan siswa, (4) menangani siswa yang pasif, (5) menarik dan mempertahankan perhatian siswa terhadap kegiatan pembelajaran.

Pembelajaran kooperatif menurut Main Sufanti (Sufanti, 2010), merupakan sistem pembelajaran yang memberikan kesempatan kepada siswa untuk bekerja sama dalam kelompok kecil. Hal ini dipertegas oleh Slavin (Slavin, 2010) dimana pada kelas kooperatif siswa diharapkan saling membantu, saling mendiskusikan dan berargumentasi, mengasah pengetahuan yang dikuasainya dan menutup kesenjangan dalam pemahaman. Pembelajaran kooperatif merupakan strategi yang menempatkan siswa dalam kelompok 4-6 siswa dengan tingkat kemampuan, jenis kelamin, latar belakang yang berbeda untuk mencapai tujuan yang sama (Isjoni, 2010). Pendapat Miftahul Huda (Huda, 2014) lebih menegaskan bahwa pembelajaran kooperatif mampu memberikan pengaruh signifikan terhadap pencapaian akademik siswa. Sehingga dapat disimpulkan pembelajaran kooperatif merupakan strategi pembelajaran yang dilakukan dengan cara mengelompok siswa dalam kelompok kecil dengan sifat keanggotaan yang heterogen untuk mencapai tujuan yang sama.

Model pembelajaran kooperatif tipe jigsaw dapat diterapkan untuk meningkatkan aktivitas siswa dalam proses pembelajaran. Siswa terlibat langsung dalam pembelajaran dan siswa tidak akan berperilaku yang tidak sesuai dan menganggu proses belajar mengajar. Melalui pembelajaran kooperatif tipe jigsaw diharapkan dapat melatih siswa agar terbiasa berdiskusi dan

Jurnal Sikola: Jurnal Kajian Pendidikan dan Pembelajaran Vol. 2, No. 2, Th. 2020 
bertanggungjawab baik secara individu dalam membantu memahami materi pokok kepada teman sekelasnya. Menurut Wina \{Formatting Citation\} aktivitas merupakan segala perbuatan siswa yang dirancang oleh guru untuk memfasilitasi kegiatan belajar siswa seperti kegiatan diskusi, demonstrasi, simulasi, serta melakukan percobaan. Tinggi rendahnya aktivitas siswa dalam belajar dipengaruhi oleh strategi atau pendekatan mengajar. Aktivitas siswa berbentuk aktivitas fisik, mental dan intelektual.

Sintak pemebelajaran kooperatif tipe jigsaw menurut (Huda, 2014) memiliki enam langkah atau tahapan pada pembelajaran diantaranya sebagai berikut: (a) fase 1, menyampaikan tujuan dan memotivasi siswa, (b) fase 2, menyajikan informasi, (c) fase 3, mengorganisasikan siswa ke dalam kelompok kooperatif, (d) fase 4, membimbing kelompok bekerja dan belajar, (e) fase 5, evaluasi, dan (f) fase 6, memberi penghargaan.

Model pembelajaran kooperatif tipe jigsaw dirancang untuk memotivasi siswa agar saling membantu antara siswa satu dengan yang lain pada saat menguasai keterampilan atau pengetahuan yang disajikan oleh guru. Aktivitas siswa dalam belajar tersebut harus terjadi di dalam kelompok siswa. Menurut Maya (Nurfitriyanti, 2017) pembelajaran Kooperatif Jigsaw dapat berpengaruh terhadap kecerdasan emosioanl siswa. Selain itu, menurut Rahma Fitri (Fitri \& Sylvia, 2020) pembelajaran kooperatif dapat meningkatkan prestasi belajar.

Pada pembelajaran kooperatif tipe jigsaw guru membagi siswa dalam kelompok kecil. Hal ini dimaksudkan agar interaksi antar siswa menjadi maksimal dan efektif. Kelompok kecil tersebut adalah kelompok asal dan kelompok ahli. Menurut Agus Suprijono (Suprijono, 2013) Jumlah kelompok asal maupun kelompok ahli tergantung pada konsep yang terdapat pada materi yang akan dipelajari. Kelompok asal yaitu kelompok induk yang beranggotakan siswa dengan beragam kemampuan dan latar belakangnya. Pada kelompok asal ini setiap anggota memiliki tugas untuk mempelajari konsep-konsep yang berbeda. Setiap siswa dari masing-masing kelompok asal yang memiliki tugas yang sama berkumpul dalam satu kelompok baru yang disebut dengan kelompok ahli. Dengan demikian kelompok ahli adalah kelompok siswa yang memiliki tugas untuk mempelajari konsep-konsep yang sama. Konsep-konsep tersebut harus dikuasai oleh setiap anggota kelompok ahli, dan konsep tersebut akan menjadi materi keahliannya. Setelah kelompok ahli selesai mempelajari suatu konsep tertentu, masing-masing siswa dari kelompok ahli ini kembali ke kelompok asal mereka, untuk mengajarkan materi keahliannya kepada teman-temannya dalam satu kelompok diskusi.

\section{Metode Penelitian}

Penelitian ini menggunakan desain eksperimen kelompok kontrol tanpa tes.. Pada akhir pembelajaran subjek tidak diberikan tes dan diganti dengan pengamatan aktivitas subjek belajar IPA. Akhir penelitian dicari rata-rata aktvitas belajar IPA dari dua kelompok untuk dicari perbedaanya, dengan maksud untuk mengetahui ada tidaknya pengaruh model pembelajaran. Kelompok eksperimen menggunakan pembelajaran kooperatif jigsaw siswa kelas IVA SDN 12 Entikong dan kelas kontrol pembelajaran konvesional siswa kelas IVB SDN 12 Entikong.

Penelitian dilakukan di SDN 12 Entikong Kabupaten Sanggau Kalimantan Barat, dimana sekolah tersebut berbatasan langsung dengan Negara Malaysia Indonesia dan sekolah tersebut sebagai rujukan di UPT Kecamatan untuk sekolah dasar daerah perbatasan.

Pada penelitian ini, peneliti melakukan observasi untuk mengetahui pengaruh model pembelajaran Kooperatif Tipe Jigsaw terhadap aktivitas belajar IPA pada siswa kelas IV SDN 12 Entikong. Observasi dilakukan sebelum dan sesudah diberi perlakuan pada kedua kelas yaitu kelas eksperimen dan kelas kontrol. Siswa pada kelas eksperimen berjumlah 22 orang sedangkan pada kelas kontrol berjumlah 20 orang. Kelas eksperimen diberikan perlakuan menggunakan pembelajaran Kooperatif Tipe Jigsaw, sedangkan kelas kontrol pembelajaran konvesional. Instrumen yang digunakan adalah lembar observasi rating scale pada aktivitas belajar siswa. Aspek aktivitas belajar siswa meliputi aktivitas visual, lisan, mendengar, menulis, menggambar,

Jurnal Sikola: Jurnal Kajian Pendidikan dan Pembelajaran Vol. 2, No. 2, Th. 2020 
mental dan emosional pada pelajaran IPA. Sebelumnya, instrumen yang dibuat dan digunakan penelti sudah divalidasi dengan expert judgment. Data yang diperoleh kemudian dianalisis menggunakan deskriptif dan uji hipotesis untuk mengetahui apakah terdapat pengaruh penerapan pembelajaran Kooperatif Tipe Jigsaw terhadap aktivitas belajar siswa pada pelajaran IPA.

Metode analisis yang digunakan pada penelitian ini adalah statistik deskriptif dan uji hpetosis, terlebih duhulu data dianalisis menggunakan analisis dskritif, uji persyaratan dan uji hipotesis. Uji prasyaratan yang dilakukan adalah uji normaltas seberapa data dan uji homogenitas varians.

Data yang diperoleh dalam statistik deskriptif adalah data yang diperoleh pada kelas eksperimen dan kelas kontrol sebelum dan sesudah diberikan perlakuan. Pada analisis ini, dihasilkan deskripsi berupa tabel. Pada analisis deskriptif terdapat pengujian nilai mean, median, modus, standar deviasi, nilai maksimal dan nilai minimal.

Pengujian normalitas sebaran data dilakukan terhadap 2 kelompok data. Untuk mengetahui normalitas sebaran data digunakan rumus Komograv Smirnov dengan bantuan SPSS 24.0 for windows. Sedangkan pengujian homogenitas varians dilakukan dengan menggunakan uji Levne dengan bantuan SPSS 24.0 for windows. Setelah persyaratan analisis data diuji, selanjutnya dilakukan uji hiotesis terhadap data yang diperoleh dengan analisis Uji-T (Independent Sampl Ttes) dengan menggunkan program SPSS 24.0 for windows. Yang diuji adalah perbedaan aktivitas belajar siswa pada pembelajaran IPA kelas eksperimen dan kelas kontrol setelah perlakuan. Perhitungan statistik $t_{\text {hitung }}$ menghasilkan nilai yang leih besar atau sama dengan nilai $t_{\text {teoritik }}$ dalam tabel $\left(t_{\text {hitung }} \geq t_{\text {tabel }}\right)$ untuk $\alpha=0.05$ maka $\mathrm{H}_{\mathrm{o}}$ ditolak dan $\mathrm{H}_{\mathrm{a}}$ diterima. $\mathrm{H}_{\mathrm{o}}$ ditolak maka terdapat perbedaan aktivitas belajar siswa pada kelas eksperimen dan kelas kontrol. $\mathrm{H}_{\mathrm{o}}$ diterima maka tidak terdapat perbedaan aktivatas belajar siswa pada kelas eksperimen dan kelas kontrol.

\section{Hasil dan Pembahasan}

\section{Hasil}

Hasil penelitian ini diambil dari pengamatan kegiatan pembelajaran pada siswa kelas IVA dan kelas IVB di SDN 12 Entikong. Proses pembelajaran eksperimen menggunakan pembelajaran kooperatif jigsaw pada kelas IVA dan pembelajaran konvisioanal ada siswa kelas IVB. Pada pembelajaran lebih mengutamakan pada aktivitas siswa ada proses pembelajaran kooperatif jigsaw. Adapun aspek aktivitas belajar siswa terdapat delapan aspek. Aspek belajar siswa dapat dilihat pada tabel 1.

Tabel 1. Nilai Rata-Rata Aspek Aktivitas Belajar Siswa Pertemuan I

\begin{tabular}{clcc}
\hline No & Aspek Pengamatan & $\mathbf{X}$ & $\mathbf{Y}$ \\
\hline 1 & Visual & 3,63 & 2,76 \\
\hline 2 & Lisan & 2,82 & 3,51 \\
\hline 3 & Mendengarkan & 3,18 & 3,32 \\
\hline 4 & Menulis & 2,89 & 1,93 \\
\hline 5 & Menggambar & 2,32 & 0,00 \\
\hline 6 & Metrik & 1,43 & 1,33 \\
\hline 7 & Mental & 2,48 & 3,50 \\
\hline 8 & Emosional & 2,44 & 2,71 \\
\hline
\end{tabular}


Tabel 2. Nilai Rata-Rata Aspek Aktivitas Belajar Siswa Pertemuan II

\begin{tabular}{clcc} 
No & \multicolumn{1}{c}{ Aspek Pengamatan } & $\mathbf{X}$ & $\mathbf{Y}$ \\
\hline 1 & Visual & 3,65 & 2,54 \\
\hline 2 & Lisan & 2,92 & 3,27 \\
\hline 3 & Mendengarkan & 3,18 & 3,09 \\
\hline 4 & Menulis & 3,08 & 1,76 \\
\hline 5 & Menggambar & 2,36 & 0,00 \\
\hline 6 & Metrik & 1,43 & 1,20 \\
\hline 7 & Mental & 2,57 & 3,25 \\
\hline 8 & Emosional & 2,56 & 2,64 \\
\hline
\end{tabular}

Pada aspek aktivitas belajar siswa kelas eksperimen pembelajaran kooperatif tipe jigsaw dan kelas kontral dengan pembelajaran konvisional pada pertemuan ke I dan pertemuan ke II dapat dilihat pada gambar 1 dan gambar II.

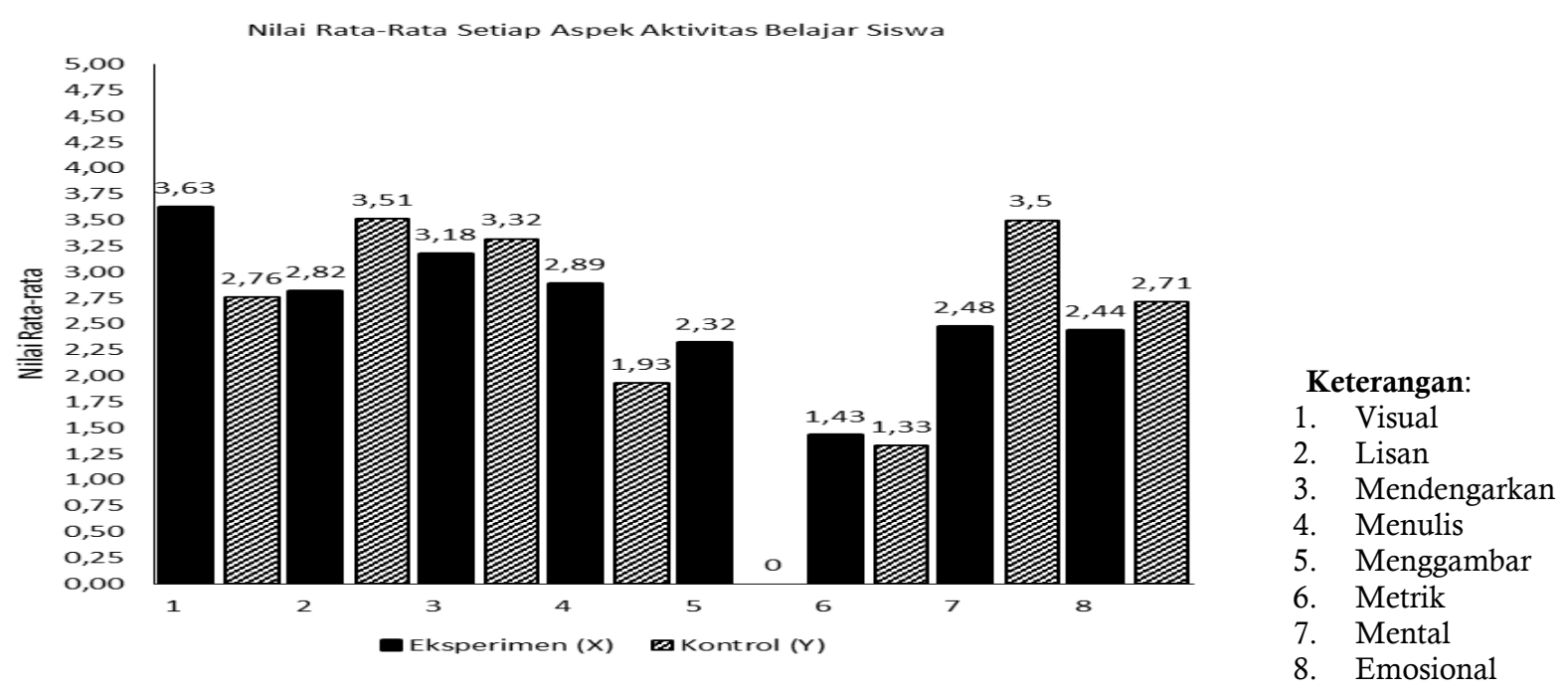

Grafik 1 Nilai Rata-rata Setiap Aspek Aktivitas Belajar Pertemuan ke I

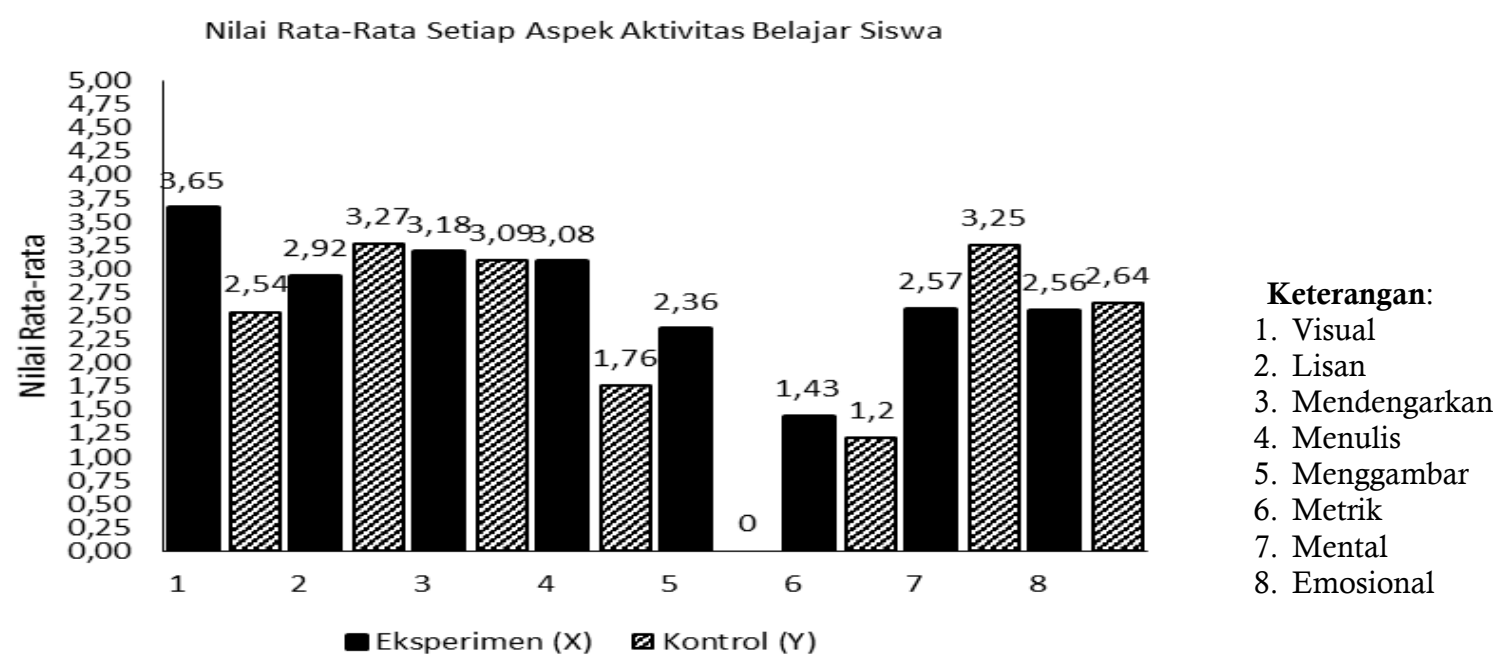

Gambar 2 Nilai Rata-rata Setiap Aspek Aktivitas Belajar Pertemuan ke II

Jurnal Sikola: Jurnal Kajian Pendidikan dan Pembelajaran Vol. 2, No. 2, Th. 2020 
Tabel 3 Deskripsi Ukuran Rata-rata Aktivitas Siswa Pertemuan ke I

\begin{tabular}{clcc} 
No & Deskripsi Ukuran Rata-rata & Eksperimen & Kontrol \\
\hline 1 & Mean & 82,55 & 80,00 \\
\hline 2 & Median & 82,50 & 80,00 \\
\hline 3 & Mode & 84,00 & 80,00 \\
\hline 4 & Standar Dev. & 3,433 & 1,487 \\
\hline 5 & Std Err Mean & 0,732 & 0,332 \\
\hline 6 & Maksimun & 89 & 83 \\
\hline 7 & Minimun & 76 & 77 \\
\hline \multicolumn{2}{r}{$N$} & 22 & 20 \\
\hline
\end{tabular}

Tabel 4 Deskripsi Ukuran Rata-rata Aktivitas Siswa Pertemuan ke II

\begin{tabular}{clcc}
\hline No & Deskripsi Ukuran Rata-rata & Eksperimen & Kontrol \\
\hline 1 & Mean & 84,55 & 82,00 \\
\hline 2 & Median & 84,50 & 82,00 \\
\hline 3 & Mode & 86,00 & 82,00 \\
\hline 4 & Standar Dev. & 3,43 & 1,49 \\
\hline 5 & Std Err Mean & 0,732 & 0,332 \\
\hline 6 & Maksimun & 91 & 85 \\
\hline 7 & Minimun & 78 & 79 \\
\hline & & 22 & 20 \\
\hline
\end{tabular}

Uji hipotesis dilakukan dengan menggunakan uji-t (Independent Sampl T-tes). Hasil dari perhitungan Uji-T (Independent Sampl T-tes) dengan menggunkan program SPSS 24.0 for windows dapat dtunjukan pada tabel 5.

Tabel 5. Hasil Uji Test "t"

\begin{tabular}{|c|c|c|c|c|c|c|c|c|c|c|}
\hline \multicolumn{11}{|c|}{ Independent Samples Test } \\
\hline & & $\begin{array}{r}\text { Leven } \\
\text { Equ } \\
V a\end{array}$ & $\begin{array}{l}\text { 's Test for } \\
\text { ality of } \\
\text { riances }\end{array}$ & \multicolumn{7}{|c|}{ t-test for Equality of Means } \\
\hline & & \multirow[t]{2}{*}{$\mathrm{F}$} & \multirow[t]{2}{*}{ Sig. } & \multirow[t]{2}{*}{$t$} & \multirow[t]{2}{*}{$D f$} & \multirow{2}{*}{$\begin{array}{c}\text { Sig. } \\
\text { (2-tailed) }\end{array}$} & \multirow{2}{*}{ Mean Difference } & \multirow{2}{*}{$\begin{array}{c}\text { Std. Err } \\
\text { Diff }\end{array}$} & \multicolumn{2}{|c|}{$\begin{array}{l}\text { 95\% Confidence Interval of the } \\
\text { Difference }\end{array}$} \\
\hline & & & & & & & & & Lower & Upper \\
\hline \multirow[t]{2}{*}{$\overline{\text { Skor_Aktivitas }}$} & $\begin{array}{l}\text { Equal } \\
\text { variances } \\
\text { assumed }\end{array}$ & 10,920 & ,002 & 3,063 & 40 & ,004 & 2,545 & ,831 & 0,866 & 4,225 \\
\hline & $\begin{array}{l}\text { Equal } \\
\text { variances } \\
\text { not } \\
\text { assumed }\end{array}$ & & & 3,167 & 29,187 & ,004 & 2,545 & ,804 & 0,902 & 4,189 \\
\hline
\end{tabular}

Berdasarkan analisis data dengan menggunakan program SPSS 24.0 for windows, diketahui bahwa terdapat perbedaan skor nilai rata-rata antara model pembelajaran Kooperatif Tipe Jigsaw dengan metode konvesional. Dimana 95\% Confidence Interval of the Difference Lower sebesar 0,866 dan Upper sebesar 4,255 dengan Mean difference sebesar 2,545 dan Sig (2-tailed) ,004. Nilai d $f$ sebesar 40 dengan sig ,002. Berdasarkan tabel 5 tersebut nilai tobservasi sebesar 3,063.

Hasil analisis data terdapat perbedaan aktivitas belajar peserta didik di kelas eksperimen yang mengikuti pembelajaran menggunakan model pembelajaran kooperatif tipe jigsaw (kelas IV A) dibandingkan dengan dengan metode konvesional (kelas IV B). Nilai rata-rata kelas eksperimen 82,55 dan kelas kontrol 80,00 dengan masing-masing standar deviasi 3,433 kelas ekspermen 
pembelajaran kooperatif tipe jigsaw, sedangkan kelas metode konvesional besarnya standar deviasi 1,487. Hal tersebut dapat dilihat pada tabel 6 .

Tabel 6. Analisis Perbandingan Kelas Eksperimen dan Kontrol

\begin{tabular}{c|l|l|l|c|c}
\hline \multicolumn{5}{|c}{ Group Statistics } \\
\hline \multirow{2}{*}{ Skor_Aktivitas } & Kelompok_Kela & N & Mean & Std. Deviation & Std. Error Mean \\
\cline { 2 - 6 } & Eksperimen & 22 & 82,55 & 3,433 &, 732 \\
\hline
\end{tabular}

\section{Pembahasan}

Pada penelitian ini pembelajaran ada dua kelas. Kelas IVA dimana menggunakan pembelajaran kooperatif tipe jigsaw sebagai kelas eksperimen, sedangkan kelas IVB menggunakan pembelajaran konvesional sebagai kontol. Pada proses pembelajaran peneliti lebih fokus terhadap aktivitas belajas siswa kelas IV pada pelajaran IPA. Dimana aktivitas belajar siswa tersebut terdapat delapan aspek diantaranya sebagai berikut: (1) visual activities, (2) oral activities, (3) listening activities, (4) writing activities, (5) drawing activities, (6) motor activities, (7) mental activities dan, (8) emotional activities. Menurut Muhlisin pembelajaran kooperatif jigsaw dapat meningkatkan keaktifan siswa. Begitu juga dengan Menurut Wondal \& Djamrud (Suparman, Wondal, 2014) pembelajaran kooperatif tipe jigsaw dapat meningkatkan aktivias belajar siswa pada pelajaran ipa. Sedangkan menurut Nurfitriyanti pembelajaran kooperatif tipe jigsaw dapat meningkatkan prestasi aktivitas emosional pada siswa. Selain itu menurut Sugestiningsih \& Sudrajat (Asra, 2009) pembelajaran kooperatif tipe jigsaw dapat meningktkan karakter siswa.

Berdasarkan kelompok eksperimen, skor rata-rata aktivitas belajar siswa lebih tinggi dibandingkan dengan skor rata-rata kelompok kontrol. Hal ini terjadi karena empat aspek aktivitas belajar siswa diantara berupa aspek visual, aspek menulis, aspek menggambar, dan metric pada kelompok eksperimen memiliki skor lebih tinggi dibandingkan dengan kelompok kontrol. Perbedaan tersebut disebabkan siswa kelas eksperimen diberikan model pembelajaran yang menuntut siswa untuk merancang sendiri prosedur percobaan sesuai dengan lembar kerja siswa pada percobaan benda bergetar sebagai sumber bunyi dan mengenal berbagai bunyi yang dihasilkan dari botol yang telah siswa terima. Sehingga setiap siswa dapat mempersiapkan alat dan bahan secara mandiri. Sedangkan siswa kelas kontrol tidak diberikan penugasan untuk merancang sendiri prosedur percobaan yang akan dilakukan, sehingga dalam menyiapkan alat dan bahan percobaan masih ketergantungan pada petunjuk dari guru.

Kegiatan merancang percobaan juga membuat setiap siswa sudah tahu bagaimana menggunakan alat dan bahan melalui studi pustaka. Dengan demikian model pembelajaran kooperatif tipe jigsaw berpengaruh terhadap aktivitas belajar siswa. Hal ini selaras dengan pernyataan Trianto (Trianto, 2011) bahwa pembelajaran kooperatif dapat meningkatkan kinerja siswa dalam tugas-tugas akademik. Kinerja siswa yang dimaksud tidak lain adalah aktivitas belajar siswa, dan didukung oleh Isjoni (Isjoni, 2010) bahwa dalam pembelajaran kooperatif, siswa terlibat aktif pada proses pembelajaran. Selain itu siswa terlibat aktif pada proses pembelajaran. Selain itu, Trianto juga menyatakan pembelajaran kooperatif tipe jigsaw dapat melatih karakter tanggung jawab siswa dalam pembelajaran, serta dapat meningkatkan keaktifan dan prestasi belajar siswa.

Perhitungan dengan menggunakan program SPSS 24 diperoleh bahwa $t_{\text {observasi }}$ sebesar 3,063. Nilai $t_{\text {tabel }}$ dalam distribusi t pada taraf signifikansi $\alpha=5 \%$, dan $\alpha=1 \%$ dengan derajat kebebasan (df) n-2 atau $42-2=40$, masing-masing adalah 2,02 dan 2,71. Jadi tobservasi lebih besar dari $t_{\text {tabel }}$ dengan demikian hipotesis nihil (Ho) yang menyatakan tidak terdapat pengaruh penerapan model pembelajaran kooperatif tipe jigsaw yang signifikan terhadap aktivitas belajar IPA pada siswa kelas IV SDN 13 Entikong ditolak dan hipotesis alternatif ( $\mathrm{Ha}$ ) yang

Jurnal Sikola: Jurnal Kajian Pendidikan dan Pembelajaran Vol. 2, No. 2, Th. 2020 
menyatakan terdapat pengaruh penerapan model pembelajaran kooperatif tipe jigsaw yang signifikan terhadap aktivitas belajar IPA pada siswa kelas IV SDN 13 Entikong, diterima.

Model pembelajaran kooperatif merupakan model pembelajaran yang menekankan sikap atau perilaku bersama dalam bekerja atau membantu diantara sesama dalam struktur kerjasama yang teratur dalam kelompok. Hal tersebut sesuai dengan pendapat Isjoni (Isjoni, 2010) bahwa model pembelajaran kooperatif tipe jigsaw tidak hanya unggul dalam membantu siswa memahami konsep yang sulit, tetapi juga sangat berguna menumbuhkan kemampuan berpikir kritis, bekerja sama dan membantu teman. Pada proses pembelajaran siswa terlibat aktif, sehingga memberi dampak positif terhadap kualitas interaksi dan komunikasi yang berkualitas, serta dapat memotivasi siswa untuk meningkatkan prestasi belajar. Model pembelajaran kooperatif tipe jigsaw menuntut siswa bertanggung jawab secara individu sekaligus kelompok.

Pada proses pembelajaran materi dipelajari tidak hanya materi yang diberikan oleh guru, melainkan siswa juga diajak untuk memberikan dan mengajarkan materi tersebut pada anggota kelompok yang lain. Siswa dituntut untuk mempresentasikan hasil kerja kelompok. Pada presentasi siswa dianjuran untuk berperan atktif menanggapi dari temen kelompok yang mempresentasikan materi tersebut. Keadaan tersebut mendukung siswa dalam kelompoknya agar bisa belajar bekerjasama dan tanggung jawab sampai suksesnya tugas dalam kelompok pada saat berlangsung presentasi.

Model pembelajaran ini dipandang sebagai model pembelajaran yang dapat memotivasi siswa untuk mempelajari materi dengan baik (Rovin, 2006). Bentuk dari siswa yang termotivasi ditunjukan pada aspek visual, lisan, mendengar, menulis, menggambar, metrik (mengukur), mental dan emosional. Model pembelajaran ini mampu mendorong siswa bertanggungjawab pada pembelajarannya sendiri orang lain. Setiap anggota kelompok bertanggungjawab terhadap keberhasilan kelompoknya dan ketuntasan materi yang dipelajari. Siswa tidak hanya mempelajari materinya sendiri, tapi harus siap mengajarkan materi yang dia pelajari tersebut kepada teman lain dalam kelompoknya. Maka karakter tanggung jawabnya terhadap pembelajaran akan terbentuk dengan kuat. Hal ini sesuai dengan satu prinsip pembelajaran kooperatif tipe jigsaw yang dikemukakan oleh Miftahul Huda (2014), dalam belajar kooperatif siswa memiliki dua tanggung jawab, yaitu mengerjakan/memahami materi/tugas bagi keberhasilan dirinya dan anggota kelompoknya.

Pada kegiatan pembelajaran menggunakan model kooperatif tipe jigsaw, setiap siswa dalam kelompok ahli menyampaikan materi pembelajaran kepada teman yang lain dalam kelompok asal dalam waktu yang bersamaan, sehingga hal ini menyebabkan adanya suasana kelas yang bising dan memungkinkan lingkungan kelas kurang kondusif. Selain itu, adanya berpindahan aktif siswa dari kelompok asal ke kelompok ahli dan kembali lagi ke kempok asal dengan waktu tertentu yang terbatas, memungkinkan lingkungan kelas menjadi berantakan. Dengan demikian dalam kegiatan pembelajaran yang seperti ini siswa dapat dituntut untuk bertanggung jawab terhadap lingkungan kelas dengan sebaik-baiknya. Uraian tersebut sesuai dengan pendapat yang dikemukakan oleh Robert E Slavin, model pembelajaran kooperatif tipe jigsaw, siswa bekerja dalam tim-tim yang bersifat heterogen.

\section{Kesimpulan}

Berdasarkan analisis data dan pengujian hipotesis dapat disimpulkan bahwa ada pengaruh positif dan signifikan penerapan model pembelajaran kooperatif jigsaw terhadap aktivitas belajar IPA pada siswa kelas IV SDN 12 Entikong. Berdasarkan uji t test dengan SPSS 24 maupun uji dengan menggunakan rumus diperoleh $t_{\text {observasi }}>t_{\text {tabel }}$ yaitu 3,063 $>2,02$ (pada taraf signifikan 5\%) dan 3,063 > 2,271 (pada taraf signifikan 1\%) dengan nilai probabilitas signifikansi $<0,05$ yaitu 0,004 . Sedangkan besarnya pengaruh penerapan model pembelajaran kooperatif jigsaw terhadap aktivitas belajar siswa kelas IV SDN 12 Entikong pada mata pelajaran IPA adalah 2,55. Hal ini 
didasarkan atas analisa dengan menggunakan SPSS 24 diperoleh bahwa rata-rata skor pada kelas eksperimen sebesar 82,55 sedangkan pada kelas kontrol sebesar 80,00.

\section{Daftar Pustaka}

Asra, S. (2009). Sumiati dan Asra (2007). Bandung: CV. Wacana Prima.

Fitri, R., \& Sylvia, I. (2020). Pengaruh Model Pembelajaran Kooperatif Tipe Snowball Throwing Terhadap Hasil Belajar Sosiologi Siswa Kelas XI IIS Pada Materi Konflik Sosial di SMA N 1 Batusangkar. Jurnal Sikola: Jurnal Kajian Pendidikan dan Pembelajaran, 1(3), 238-244. https://doi.org/10.24036/sikola.v1i3.34

Huda, M. (2014). Cooperative Learning Metode, teknik, Struktur dan Model Penerapan. Yogyakarta: Pustaka Pelajar.

Isjoni. (2010). pembelajaran kooperatif meningkatkan kecerdasan antar peserta didik. Yogyakarta: Pustaka Belajar.

Mardian, W., \& Sylvia, I. (2020). Upaya Meningkatkan Keaktifan Belajar Melalui Penerapan Model Students Divisions Achievement Divisions di XI IPS 1 SMANegeri 1 Bukittinggi. Jurnal Sikola: Jurnal Kajian Pendidikan dan Pembelajaran, 1(3), 207-214. https://doi.org/10.24036/sikola.v1i3.31

Nurfitriyanti, M. (2017). Pengaruh Model Pembelajaran Kooperatif Tipe Jigsaw Terhadap Hasil Belajar Matematika ditinjau dari Kecerdasan Emosional. Jurnal Ilmiah Pendidikan MIPA, $7(2), 153-162$.

Slavin. (2006). Educational Psychology: Theory and Practice (8th ed). Boston: Pearson Education, Inc.

Slavin. (2010). Cooperative Learning Teori, Riset dan Praktik. Bandung: Nusa Media.

Sardiman, A. (2014). Interaksi dan Motivasi Belajar Mengajar. Jakarta: Rajawali Pers

Sufanti, M. (2010). Strategi Pembelajaran Bahasa Indonesia. Surakarta: Yuma Pustaka.

Suparman, S \& Wondal, W. (2014). Penerapan Model Pembelajaran Kooperatif Tipe Jigsaw Untuk Meningkatkan Aktivitas Dan Hasil Belajar IPA Pada KonsepPencemaran Lingkungan. Jurnal ßIOêduKASI, 3(1), 294-298.

Sanjaya, W. (2016). Strategi Pembelajaran Berorientasi Standar Proses Pendidikan. Jakarta: Kencana Prenada Media Group.

Suprijono, A. (2013). Cooperative Learning Teori dan Aplikasi Paikem. Yogyakarta: Pustaka Pelajar. Trianto, T. (2011). Mendesain Model Pembelajaran Inovatif-Progresif. Jakarta: Kencana Prenada Media Group. 